Indexed by

Scopus

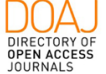

Crossref

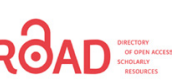

KOBSON

\section{Zhalil O. Kuluev}

Osh Technological University named after M.M. Adyshev, Department of Electric Power Engineering, Osh, Kyrgyz Republic

\author{
Nurzhamal T. Aldasheva \\ Osh Technological University \\ named after M.M. Adyshev, \\ Department of Electric \\ Power Engineering, Osh, \\ Kyrgyz Republic
}

\author{
Baktybek S. Childebaev \\ Osh Technological University \\ named after M.M. Adyshev, \\ Department of Electric \\ Power Engineering, Osh, \\ Kyrgyz Republic
}

\author{
Malika S. Elchieva \\ Osh Technological University \\ named after M.M. Adyshev, \\ Department of Electric \\ Power Engineering, Osh, \\ Kyrgyz Republic
}

Key words: thermal energy, ionization, water heating, coefficient of efficiency doi:10.5937/jaes0-30997

Cite article:

Akmatov Zh. B., Aldasheva T. N., Childebaev S. B., Kuluev O. Z., Elchieva S. M. (2021) THE DEPENDENCE OF THE COEFFICIENT OF EFFICIENCY (CE) OF THE HEATING INSTALLATION "EFI" UPON THE INITIAL TEMPERATURE OF THE HEAT-CARRYING AGENT, Journal of Applied Engineering Science, 19(4), 942 - 947, DOI:10.5937/ jaes0-30997

Online aceess of full paper is available at: www.engineeringscience.rs/browse-issues 


\title{
THE DEPENDENCE OF THE COEFFICIENT OF EFFICIENCY (CE) OF THE HEATING INSTALLATION "EFI" UPON THE INITIAL TEMPERATURE OF THE HEAT-CARRYING AGENT
}

\author{
Baatyr Zh. Akmatov*, Nurzhamal T. Aldasheva, Baktybek S. Childebaev, Zhalil O. Kuluev, Malika S. Elchieva \\ Osh Technological University named after M.M. Adyshev, Department of Electric Power Engineering, Osh, \\ Kyrgyz Republic
}

The purpose of the study is to determine the increase in the efficiency of the electrophysical ionization device on a scientific basis, which produces thermal energy based on the regularity of the electrophysical ionization process. This research article discusses the dependence of the amount of thermal energy obtained in the device of electrophysical ionization on temperature. It is noted that if in the case of the traditional method of heating the substance used in the heating industry, the relative heat capacity of the substance is important, then when heated by an unconventional method, in other words, the temperature of the substance is important in the electrophysical ionization device. This indicator, determined on the basis of the experiment, emphasizes the need to apply depending on the correct choice of the physical parameters of the substance the electrophysical ionization method for the efficient production of thermal energy in the heating industry from the heat-carrying substance. Although the heating of water is mainly carried out using various well-known traditional and non-traditional methods, the natural law of heating water is unique. This law notes the dependence of the magnitude of changes in the internal energy of water in a certain volume of heated water and on the speed of movement of this mass. Considering from the point of view of the regularity of the above direction, it is noted that in order to compare the water heated by the traditional method, appropriate calculations have been made.

Key words: thermal energy, ionization, water heating, coefficient of efficiency

\section{INTRODUCTION}

The importance of direct and indirect influence of thermal energy on raising the living standards of society on earth is noted; therefore, the use of thermal energy in industry and in everyday life continues ad infinitum. At the same time the production of thermal energy by burning combustible substances (wood, briquettes, coal, oil products, shale, etc.) has been known since ancient times. However, it has been scientifically confirmed that the generation of heat in this direction is accompanied by a low indicator of efficiency and the appearance of environmental problems.

If we take into account environmental problems, then solar and electric energy are considered promising as a source of thermal energy. However, solar energy is not always sufficient. Therefore, as a priority direction for generating thermal energy, it is possible to refer to electrical energy (but, it is necessary to take into account the harmful sides of nuclear power plants, atomic energy is not safe). Generation of thermal energy from electrical energy is produced in traditional and nontraditional directions ("super unit devices"). As practice shows, in the heating system water heaters are widely used. The fact that there are currently many ways to heat water through the use of electrical energy, which has not been scientifically based on the fact that there is an effective (optimal) way to heat water, proves the existence of the problem and its relevance.

Water heating is widely used in the heating industry. Wa- ter heating is performed by various methods. We know traditional heating - by supplying heat outside (coal, gas, fuel oil, etc.) and electric water heaters. In addition, there are new sources of energy based on: cavitation methods [1], household heat generator of Viktor Schauberger [2], vortex heat generator (VHG) of A. Potapov and "super unit" heat generator [3]. If the thermal energy produced is greater than the mechanical energy required for operating a hydraulic or other electric machine, the installation is called "super unit". The term "super unit" thermal generator was introduced into science by L.P. Fominskii, who noted the creators of the "super unit" design [4-6].

We know that A. Rossi's generator receives 3.74 times more thermal energy than consumed electrical energy [7]. However, this generator uses nickel powder. A. Rossi believes that the source of energy in this heat generator is cold nuclear fusion [7, 8]. In addition to the above, an unconventional method of generating heat from water also includes the process of electrophysical ionization (EFI), since it has been experimentally proven to get heat from a liquid (water) in an EFI device [9]. Due to the fact that these ways of heating water are different, you can notice the features of the last 3 ways (taking into account the efficiency). When water is heated, one of the main parameters of the indicators is efficiency. But with the traditional heating of water in this parametric index, the properties of the substance corresponding to some 
physical parameters inherent in water (liquid) are not taken into account, since with increasing water temperature some physical parameters of this substance change. Namely, the density of water and viscosity change (surface tension force, interaction force of molecules and other similar parameters). As a result, one can notice a change in the properties of a substance in [10].

As is evident in [11], with increasing water temperature, its relative heat capacity $\left(\mathrm{C}=4200 \mathrm{~J} /\left(\mathrm{kg} \cdot{ }^{\circ} \mathrm{C}\right)\right)$ does not undergo large changes $\left(4217 \mathrm{~J} /\left(\mathrm{kg} \cdot{ }^{\circ} \mathrm{C}\right)-4196 \mathrm{~J} /\right.$ $\left(\mathrm{kg} \cdot{ }^{\circ} \mathrm{C}\right)$ ). With traditional water heating, this pattern is observed. And if an EFI process is used to obtain heat from water (water heating), in other words, an EFI device (and VHG), the experimental data prove the failure of the indicated pattern. As much as the temperature of the heated water will be high, so much more is the thermal energy generated in the heat generator "EFI" (the optimum temperature for generating thermal energy is $40^{\circ} \mathrm{C} \div 65^{\circ} \mathrm{C}$ ) [11].

Thus, comparing the EFI and VHG devices and the principles of their operation, we emphasize simplicity, a very small need for materials and the efficiency of the EFI device (including at considering the initial temperature of the liquid). The experiment proves, if you look at the principle of the installation operation, the heating of water based on the EFI process is effective. So, the aim of the article is to determine the increase in the efficiency of the electrophysical ionization device, which produces thermal energy based on the regularity of the electrophysical ionization process.

\section{MATERIALS AND METHODS}

In the heating system water heating system is widely used [12]. Therefore, the relationship of increasing the efficiency of this heater with the temperature of the heat-carrying agent in the process of producing heat energy in water from other energy obtained from outside, and on the basis of them comparing water heating by the traditional method, has become the object of research. In the study of this object, the regularity of the kinetic theory of thermodynamics $[13,14]$ and the method of electrophysical ionization [15] have been applied. Out of the ways to use electrical energy in order to generate thermal energy, the EFI device is considered to be efficient, economical and convenient. If the change in the efficiency of the specified device is made in the direction of its growth, then in the study of the direction of determining the presence of such a condition on a scientific basis, a special experiment has been conducted to a certain extent with the results indicated in the second row of Table 1.

According to experimental data, the calculations have been introduced to Table 1. In these tables, the data at the intersection of the columns with the 12-row of Table 1 shows that the value of the resulting heat energy changes depending on the temperature (water density) and other parameters. Therefore, it can be determined that due to a change in the temperature or density of a substance, the efficiency value (becomes variable) also changes. It means that the experimental data point out the regularity of the change in the value of the thermal energy obtained from the substance due to the change in the properties of this substance.

Therefore, it is easy to determine that with traditional heating, the value that determines the value of all heaters is efficiency (Eq. 1), and from the patterns of the EFI process [11] (Eq. 2):

$$
\begin{aligned}
& \eta=\frac{Q_{1}-Q_{2}}{Q_{1}} \times 100 \% \\
& \eta=\frac{U \times I \times t-\left(Q-Q_{0}\right)}{U \times I \times t} \times 100 \%=\frac{U \times I \times t-Q_{e f i}}{U \times I \times t} \times 100 \%
\end{aligned}
$$

The fact that the amount of production in the EFI device thermal energy is variable can be seen in Table 1. Therefore, there is every reason to assert that the value of the efficiency of production of thermal energy in the device EFI is variable depending on the temperature of the heat-carrying agent (water). We note a feature of the operation of an EFI device when receiving heat energy from water (liquid). On the basis of the corresponding calculations on the values at the intersection of the 7th and 12 th rows with the 7 th column of Table 1 , the obtained experimental data determined that each of their molecules, ionizable in the bulk of the molecules, gives $0.28 \mathrm{eV}$ of energy. At the same time, compared with the 6 th column, the energy has increased by 1.89 times. A fundamental difference of VHG is that electricity is consumed only on the electric pump, pumping water, and water produces additional thermal energy. Additional energy from water is generated by combining associates. Each molecule yields from 0.24 to $0.50 \mathrm{eV}$ of energy [16].

We know that thermal energy is the random (Brownian) motion of a substance molecule [17]. Considering from this point of view, the possibility of using thermal energy to obtain thermal energy by various methods has been noted above. However, not in all cases the velocity of the heated water molecule changes. As a result, the temperature of the heated water (liquid) is changed by different values.

That is why the production of thermal energy from electrical energy is proved by the results obtained from experimental indicators. For example, $1 \mathrm{~m}^{3}$ of electrolysis space has the ability to absorb $400 \mathrm{~kW}$ of electricity, this results in $1000 \mathrm{~kW}$ of thermal energy [18]. In addition, as evidenced by experimental data obtained in the process of electrophysical ionization, the achievement in a short time of a large change in the internal energy of water (liquid) in the volume and, as a result, the energy obtained in this volume (kinetic energy) of substance movement also produces thermal energy [11]. As the experiment proves, the pattern of generating thermal energy from electrical energy in the process of electrophysical ionization (EFI), taken from [11], is described below (Eqs. 3, 4):

$$
Q=Q_{e f i}+Q_{0}
$$


Table 1: The dependence of the amount of thermal energy obtained by the electrophysical ionization method on the temperature of water (liquid)

\begin{tabular}{|c|c|c|c|c|c|c|c|c|}
\hline No & Physical options & $\begin{array}{c}32^{\circ} \mathrm{C} \\
\left(22^{\circ}-42^{\circ} \mathrm{C}\right) \\
\end{array}$ & $\begin{array}{c}52^{\circ} \mathrm{C} \\
\left(42^{\circ}-62^{\circ} \mathrm{C}\right) \\
\end{array}$ & $\begin{array}{c}11^{\circ} \mathrm{C} \\
\left(20^{\circ}-20^{\circ} \mathrm{C}\right) \\
\end{array}$ & $\begin{array}{c}30^{\circ} \mathrm{C} \\
\left(20^{\circ}-40^{\circ} \mathrm{C}\right) \\
\end{array}$ & $\begin{array}{c}50^{\circ} \mathrm{C} \\
\left(40^{\circ}-60^{\circ} \mathrm{C}\right) \\
\end{array}$ & $\begin{array}{c}70^{\circ} \mathrm{C} \\
\left(60^{\circ}-80^{\circ} \mathrm{C}\right) \\
\end{array}$ & $\begin{array}{c}31^{\circ} \mathrm{C} \\
\left(21^{\circ}-41^{\circ} \mathrm{C}\right)\end{array}$ \\
\hline 1 & $U(B)$ & 157.0 & 157.0 & 157.0 & 157.0 & 157.0 & 157.0 & 210.2 \\
\hline 2 & $\begin{array}{l}\text { The volume of ion- } \\
\text { ized liquid in the va- } \\
\text { por of the electrode } \\
\text { for } 1 \text { second (in \%) }\end{array}$ & 0.0144 & 0.0144 & 0.0288 & 0.0576 & 0.0576 & 0.0576 & 0.0576 \\
\hline 3 & \begin{tabular}{|c|}
$\begin{array}{c}\text { Generated thermal } \\
\text { energy for } 1 \text { second } \\
(\mathrm{J})\end{array}$ \\
\end{tabular} & 563.13 & 740.088 & 1260 & 2200.87 & 2446.6 & 2126.58 & 3475.86 \\
\hline 4 & $\begin{array}{c}\text { Time (seconds) } \\
\text { to increase the } \\
\text { temperature of the } \\
\text { heating water by } 1^{\circ} \mathrm{C}\end{array}$ & 44.75 & 34.05 & 22.2 & 11.45 & 10.3 & 11.85 & 7.25 \\
\hline 5 & Q/т (J/s) & 563.13 & 740.088 & $1260 / 2=630.0$ & $\begin{array}{l}2200.87 / 4 \\
=550.218\end{array}$ & $\begin{array}{c}2446.6 / 4= \\
611.6 \\
\end{array}$ & $\begin{array}{l}2126.58 / 4 \\
=531.645 \\
\end{array}$ & $\begin{array}{l}868.965 \times 4 \\
=3475.86\end{array}$ \\
\hline 6 & $\mathrm{Q}_{0}(\mathrm{~J})$ & 116.12 & 188.6976 & 39.9168 & 108.864 & 184.44 & 254.016 & 112.493 \\
\hline 7 & $Q_{\text {eft }}=Q / T(J / s)-Q_{0}(j)$ & 447.01 & 551.390 & 590.083 & 441.354 & 427.16 & 277.629 & 756.473 \\
\hline 8 & $\Delta \mathrm{T}(\mathrm{K})$ & 160.094 & 197.478 & 211.336 & 158.0690 & 152.9855 & 99.43162 & 270.92753 \\
\hline 9 & $\Delta U=Q_{1 \text { eft }}(J)$ & 255.43 & 315.080 & 337.190 & 252.2023 & 244.0914 & 158.6414 & 432.270291 \\
\hline 10 & $E_{k}=Q_{2 e f t}(J)$ & 95.787 & 118.155 & 126.446 & 94.57586 & 91.57586 & 59.49192 & 162.101359 \\
\hline 11 & $Q_{1 \text { eft }}+Q_{2 \text { eft }}(J)$ & 351.22 & 433.235 & 463.636 & 346.7781 & 335.6257 & 218.1370 & 594.37165 \\
\hline 12 & $Q_{\text {eft }}=Q_{1 \text { eft }}+Q_{2 \text { eft }}(J)$ & 447.007 & 551.390 & 590.083 & 441.354 & 427.2015 & 277.6289 & 756.473009 \\
\hline No & Physical options & $\begin{array}{c}31^{\circ} \mathrm{C} \\
\left(22^{\circ}-40^{\circ} \mathrm{C}\right)\end{array}$ & $\begin{array}{c}31^{\circ} \mathrm{C} \\
\left(21^{\circ}-41^{\circ} \mathrm{C}\right)\end{array}$ & $\begin{array}{c}49.5^{\circ} \mathrm{C} \\
\left(41^{\circ}-58^{\circ} \mathrm{C}\right)\end{array}$ & $\begin{array}{c}50^{\circ} \mathrm{C} \\
\left(41^{\circ}-59^{\circ} \mathrm{C}\right)\end{array}$ & $\begin{array}{c}31^{\circ} \mathrm{C} \\
\left(21^{\circ}-41^{\circ} \mathrm{C}\right)\end{array}$ & $\begin{array}{c}51^{\circ} \mathrm{C} \\
\left(41^{\circ}-50^{\circ} \mathrm{C}\right)\end{array}$ & $\begin{array}{c}49^{\circ} \mathrm{C} \\
\left(41^{\circ}-57^{\circ} \mathrm{C}\right)\end{array}$ \\
\hline 1 & $U(B)$ & 212.0 & 215.0 & 215.0 & 215.0 & 215.0 & 215.0 & 210.2 \\
\hline 2 & $\begin{array}{l}\text { The volume of ion- } \\
\text { ized liquid in the va- } \\
\text { por of the electrode } \\
\text { for } 1 \text { second (in \%) }\end{array}$ & 0.072 & 0.072 & 0.072 & 0.0864 & 0.1008 & 0.1008 & 0.0576 \\
\hline 3 & $\begin{array}{c}\begin{array}{c}\text { Generated thermal } \\
\text { energy for } 1 \text { second } \\
(\mathrm{J})\end{array} \\
\end{array}$ & 4123.63636 & 3370.484 & 6210.449 & 5079.161 & 3332.04 & 4223.85 & 3992.08 \\
\hline 4 & $\begin{array}{l}\text { Time to increase the } \\
\text { temperature of the } \\
\text { heating water by } 1^{\circ} \mathrm{C}\end{array}$ & 6.1 & 5.7 & 3.47 & 4.1 & 5.75 & 4.7 & 6.3125 \\
\hline 5 & $\mathrm{Q} / \mathrm{T}(\mathrm{J} / \mathrm{s})$ & $\begin{array}{c}824.73 \times 5= \\
4123.636 \\
\end{array}$ & $\begin{array}{l}674.1 \times 5= \\
3370.484\end{array}$ & $\begin{array}{c}1242.09 \times 5= \\
6210.449 \\
\end{array}$ & $\begin{array}{c}846.527 \times 6= \\
5079.161\end{array}$ & $\begin{array}{c}476.0058 \times 7= \\
3332.04 \\
\end{array}$ & $\begin{array}{c}4223.85 / 7 \\
=603.41 \\
\end{array}$ & $\begin{array}{c}3992.08 / 4= \\
998.02\end{array}$ \\
\hline 6 & $\mathrm{Q}_{0}(\mathrm{~J})$ & 112.493 & 112.4928 & 179.6256 & 181.44 & 112.4928 & 185.0688 & 177.81 \\
\hline 7 & $Q_{\text {eft }}=Q / T(J / s)-Q_{0}(j)$ & 712.2345 & 561.6072 & 1062.4644 & 665.087 & 363.513 & 418.3412 & 820.21 \\
\hline 8 & $\Delta \mathrm{T}(\mathrm{K})$ & 255.08 & 201.137 & 380.517 & 238.198 & 130.19 & $149.827 x$ & 293.7546 \\
\hline 9 & $\Delta U=Q_{1 \text { eft }}(J)$ & 406.99115 & 320.918405 & 607.122522 & 380.049719 & 207.721717 & 239.052117 & 468.691499 \\
\hline 10 & $E_{k}=Q_{2 \text { eft }}(J)$ & 152.62168 & 120.344402 & 227.670946 & 142.518645 & 77.895644 & 89.6445439 & 175.759252 \\
\hline 11 & $Q_{1 \text { eft }}+Q_{2 \text { eft }}(J)$ & 559.61283 & 441.262807 & 834.793468 & 522.568364 & 285.617361 & 328.696661 & 644.450751 \\
\hline 12 & $Q_{\text {eft }}=Q_{1 \text { eft }}+Q_{2 \text { eft }}(J)$ & 712.23451 & 561.607209 & 1062.4641 & 665.087009 & 363.513005 & 418.341205 & 820.210003 \\
\hline
\end{tabular}


Table 2: Details of heating water with gas (obtained by experiment)

\begin{tabular}{|c|c|c|c|c|c|}
\hline SN & $\begin{array}{c}\text { Volume of the } \\
\text { water being heated } \\
\mathbf{V}(\mathbf{I})\end{array}$ & $\begin{array}{c}\text { Initial temperature } \\
\text { of the water being } \\
\text { heated } \mathrm{T}_{\mathbf{0}}\left({ }^{\circ} \mathrm{C}\right)\end{array}$ & $\begin{array}{c}\text { Heated water tem- } \\
\text { perature } \mathrm{T}_{\mathbf{1}}\left({ }^{\circ} \mathrm{C}\right)\end{array}$ & $\begin{array}{c}\text { Water heating } \\
\text { time } \mathbf{T}(\mathbf{s e c})\end{array}$ & $\begin{array}{c}\text { Gas consumption for } \\
\text { water heating }\left(\mathbf{m}^{3}\right)\end{array}$ \\
\hline 1 & 10.0 & 15 & 78 & 51 & 0173 \\
\hline
\end{tabular}

$Q_{e f i}=\frac{m}{\mu} \times \frac{i+2}{2} \times R \times \Delta T+m \times u_{s . s q .}^{2}=Q_{1 e f i}+Q_{2 e f i}$

Here $Q_{\text {efi }}$ - thermal energy generated by electrophysical ionization in a liquid, $Q_{0}=m \times C \times \Delta t-$ thermal energy of a fluid with a temperature to in the volume between the electrodes before exposure to electrophysical ionization by means of a pair of electrodes, $\mathrm{m}$ - mass, $\mathrm{C}$ - thermal capacity of the liquid, $\mu$ is the molar mass of the substance subjected to electrophysical ionization, $\mathrm{R}$ is the universal gas constant and $u_{\text {s.kv }}^{2}$ - mean square mass velocity.

\section{RESULTS AND DISCUSSION}

We are convinced that when generating heat energy by an unconventional method in the above installation with the consumption of electrical energy, the efficiency indicators will be more than $100 \%$. On the basis of the laws indicated by (4) - the efficiency of generating thermal energy from water was considered in [11]. In addition, in contrast to electric heaters based on the Joule-Lenz law, the dependence of the efficiency index based on the regularity of the EFI of electric heaters on the temperature of the heated water (liquid), i.e., the higher the temperature of the heated water, the greater will be the indicator of efficiency. According to Table 1, the efficiency of the installation increased 1.89 times (this indicator is not the limit) [11]. According to the above direction, in order to consider the operation of the heat generator "EFI" on a scientific basis, to compare the heating of water in the traditional way, experiments and analysis of their results have been carried out.

\section{Heating water with gas}

A cylindrical material is used to heat water on gas. The diameter of its base is $24 \mathrm{~cm}$, i.e., its area is 0.0346185 $\mathrm{m}^{2}$. Information on water heating is given in Table 2.

Corresponding calculations have shown that according to the experimental data obtained, when heating 10 liters of water from $15^{\circ} \mathrm{C}$ to $78^{\circ} \mathrm{C}$ (Figure 1), the amount of heat that the water received is equal to $2.646 \mathrm{~kJ}$. It can be calculated that the Amount of heat that the water has received for 51 second of heating time is $864.7 \mathrm{~J}$. We can also determine the internal energy of which mass out of 10 liters of water will change the specified amount of heat. To determine this value, we take into account that $674.1 \mathrm{~J}$ of the amount of heat from the heat generator "EFI" changes the internal energy of $7.7 \times 10-4 \mathrm{~kg}$ of water mass [11].

Consequently, the internal energy of heated water with a mass of $9.877 \times 10^{-4} \mathrm{~kg}$ (if obtained relatively) undergoes a change in 1 second. Since the mass of water with the internal energy changed in 1 second has be- come known, it is possible to determine the thickness of this water, since the area of the base of the material (object) used to heat the water is known. In addition, the diameter of 1 water molecule is known - 3.11 x 10-10 $m$ [19]. Therefore, calculations based on experimental data prove that the thickness of water with altered internal energy is $0.02853 \mathrm{~mm}$ (obtained relatively). Corresponding calculations show that the resulting thickness is 91736.3344 times larger compared to the diameter of 1 water molecule (obtained relatively).

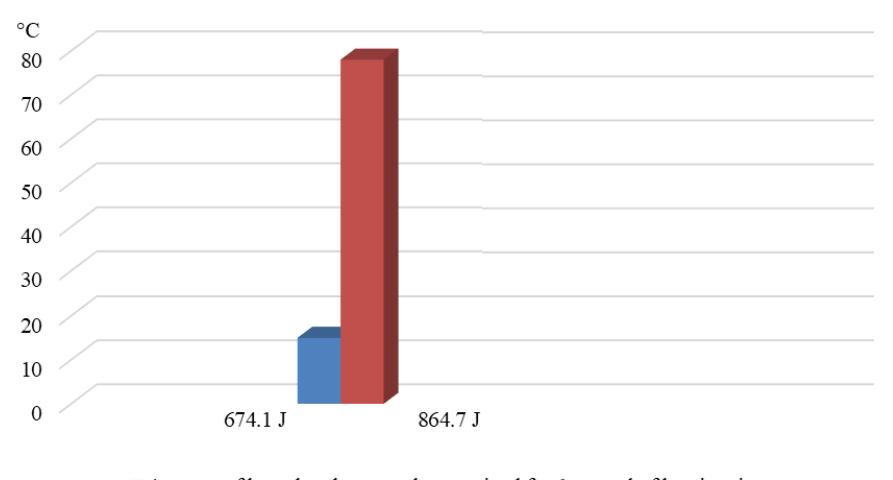

- Amount of heat that the water has received for 1 second of heating time

- Amount of heat that the water has received for 51 second of heating time

Figure 1: Heating water with gas

\section{Heating of water by the tubular electric heating element (TEFALKI150D30)}

When the water is heated, a tubular electric heating element (TEFALKI150D30) has been used; the power has been chosen to be $2000 \mathrm{~W}$. For heating water material volume of 2.65 liters (TEFALKI150D30) has been used. The diameter of the device used TEFALKI150D30 is $15.5 \mathrm{~cm}$, and the surface area is $0.01886 \mathrm{~m}^{2}$. Information on the heating of water obtained during the experiment is presented in Table 3.

The corresponding calculations from the experimental data obtained show that when 2.65 liters of water are heated from $140^{\circ} \mathrm{C}$ to $800^{\circ} \mathrm{C}$ (Figure 2), the amount of heat produced by the water is $734.58 \mathrm{~kJ}$ (It can be seen here that the feature is 74 seconds $(137-57=80 ; 216-137=$ $79 ; 294-216=78.368-294=74 ; 443-368=75$ and $518-$ $443=75)$ ). And also, as the relevant calculations show, the amount of heat produced by water in 1 second of time is $361.328 \mathrm{~J}$. You can determine the internal energy of which mass of 2.65 liters of water will change the specified amount of heat. To determine this value, we use the relevant above information on the heat generator "EFI" [11].

Therefore, since the mass of water with a changed internal energy is known for 1 second of time, it is possible to determine the thickness of the heating element in the tubular electric heating element (TEFALKI150D30) of water 
Table 3: Details of heating water with the tubular electric heating element TEFALKI150D30 (obtained by experiment)

\begin{tabular}{|c|c|c|c|c|c|c|c|}
\hline $\mathbf{N}$ & $\begin{array}{l}\text { Volume of the } \\
\text { water being } \\
\text { heated V (I) }\end{array}$ & $\begin{array}{c}\text { Initial tem- } \\
\text { perature of the } \\
\text { water being } \\
\text { heated } \mathrm{T}_{0}\left({ }^{\circ} \mathrm{C}\right)\end{array}$ & $\begin{array}{c}\text { Temperature } \\
\text { of the water } \\
\text { being heated } \\
\mathrm{T}_{1}\left({ }^{\circ} \mathrm{C}\right)\end{array}$ & $\begin{array}{c}\text { Voltage } \\
\text { (V) }\end{array}$ & $\begin{array}{l}\text { Water heat- } \\
\text { ing time T } \\
\text { (sec.) }\end{array}$ & $\mathrm{T}$ (sec.) & $\Delta \mathrm{T}=\mathrm{T} 2-\mathrm{T} 1$ (sec.) \\
\hline 1 & 2.65 & 14 & 20 & 230 & 57 & 57 & 57 \\
\hline 2 & 2.65 & 20 & 30 & 210 & $2 \mathrm{~min} .17 \mathrm{sec}$ & 137 & 80 \\
\hline 3 & 2.65 & 30 & 40 & $207-214$ & $3 \mathrm{~min} .36 \mathrm{sec}$. & 216 & 79 \\
\hline 4 & 2.65 & 40 & 50 & 218 & $4 \mathrm{~min} .54 \mathrm{sec}$ & 294 & 78 \\
\hline 5 & 2.65 & 50 & 60 & 216 & $6 \mathrm{~min} .8 \mathrm{sec}$. & 368 & 74 \\
\hline 6 & 2.65 & 60 & 70 & 216 & $7 \mathrm{~min} .23 \mathrm{sec}$ & 443 & 75 \\
\hline 7 & 2.65 & 70 & 80 & 223 & $8 \mathrm{~min} .38 \mathrm{sec}$. & 518 & 75 \\
\hline 8 & 2.65 & 14 & & 80 & & 2033 & \\
\hline
\end{tabular}

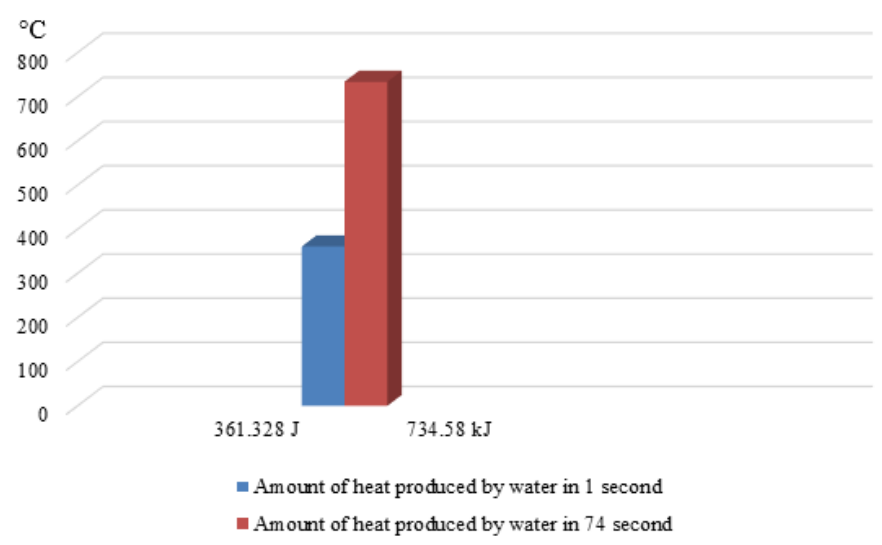

Figure 2: Heating water with the TEFALKI150D30

in a certain volume with the internal energy changed at the initial time. Also known is the area of the base used to heat water, the material (object). In addition, the diameter of 1 water molecule is known $-3.11 \times 10^{-10} \mathrm{~m}$. Therefore, calculations based on experimental data prove that the thickness of water with altered internal energy is $0.021884 \mathrm{~mm}$ (if it is obtained relatively). Corresponding calculations show that the thickness obtained is 70366.56 times larger compared to the diameter of 1 water molecule (obtained relatively).

Consequently, when water is heated by a traditional method, the process of changing a certain amount of internal energy of a certain mass of water in a volume is first performed. As a result, the mass of water in this volume will receive a certain speed, i.e., kinetic energy. As a result, the movement of water molecules from the bottom to the water surface increases over time. This process is also proved by increasing the temperature. Together with an increase in water temperature, the density of heated water decreases [10]. Such a condition will lead to an increase in the speed of the water molecule. As a result, as we learned earlier, a gradual acceleration with time of the movement of water molecules in full volume is well evident. The emergence of such conditions is not very visible when efficiently producing thermal energy from water (liquid) by the traditional method and, conversely, is clearly obvious when used to generate thermal energy from water by the method of electrophysical ionization [11]. This process is proved by the data obtained from experiments given in Table 1.

Consequently, although there are a lot of identified methods of water heating (traditional and non-traditional) used in the heating and hot water supply system, but the natural law of water heating is a single one. This law shows the dependence on the magnitude of the change in the internal energy of water in a certain volume in heated water and on the speed of movement of this mass. In other words, as much the amount of internal energy of water can be changed for a certain time and how much greater speed this mass will receive, so much and quickly the water will be heated. As the experiment proves, this process repeats over a unit of time (no matter what method of heating water is used). Therefore, when generating thermal energy from water (liquid) in comparison with all other methods in the process of electrophysical ionization, in other words, in the heat generator "EFI", the production of thermal energy is more efficient and its use is more convenient.

As a result, the generation of heat energy in the heat generator "EFI" depends not only on the power of electric power supplied from outside, but also on the material of the electrodes, the area of their surface, the distance between them. In addition, it depends on the density of water, chemical composition, temperature of heated water, sunlight and other similar external influencing processes $[9,15]$. Taking into account the efficiency of the EFI installation [9] for generating thermal energy when using electrical energy and the fact that this indicator varies depending on many physical parameters (determined on the basis of experimental data), we know that the heating of water (liquid) is mainly produced with various well-known traditional and non-traditional methods, the natural law of heating water (liquid) is one, and this law notes the dependence of the magnitude of changes in the internal energy of water in a certain amount of heated odes and speed of movement of the mass. 


\section{CONCLUSIONS}

Until now, on a scientific basis, no emphasis has been placed on a particular one method of efficiently obtaining thermal energy through the use of electrical energy, although there are many ways to heat water, taking into account the environmental issues. The pattern of the process of obtaining thermal energy from electrical energy is not scientifically noted, i.e., on a scientific basis there is no full stop in this direction; various methods of heating water are still being used. Therefore, it is necessary to scientifically substantiate the best way to heat water through the use of electrical energy. Based on the above, considering constant characteristics, parameters of continuity and environmental problems, in the production of thermal energy, electric energy has an advantage over all other energy sources. The amount of heat production from water in an EFI device, depending on the external energy supplied from outside, is related to the correct choice of the physical parameters of water in the heating system.

The dependence of the device (EFI) efficiency value when heating the heat transferring substance (water) in the heating industry on the initial temperature (density) of the heated substance (water) has been experimentally confirmed. At present, an EFI device for generation thermal energy from water compared to all existing electric heaters is more economical and efficient (including when considering the initial temperature of the liquid). Since the production of heat energy in the heat generator "EFI" is not based on the Joule-Lenz law, but on the process of electrophysical ionization, therefore the indicator of the efficiency of the installation varies depending on the temperature of the heated water. Although there are many well-known traditional and non-traditional methods of heating water, but the law of water heating is single; it is based on the amount of change in the internal energy of water in a certain volume in the heated water and the regularity of the rate of movement of this mass.

\section{ACKNOWLEDGEMENTS}

In this article, for the experimental results of water heating obtained by traditional and non-traditional methods, we would like to express our gratitude to the research staff of the "Laboratory for advanced technologies and materials" at the Institute of natural resources named after A. S. Dzhamanbayev of the Southern branch of the Kyrgyz Republic National Academy of Sciences. On the basis of the development of the electrophysical ionization method in a liquid (water), a pattern has been obtained and the installation of the heat generator "EFI" has been developed.

The research has been carried out at the expense of B.Zh. Akmatov.

\section{REFERENCES}

1. Pirsol, I. (1975). Cavitation. Mir, Moscow.
2. Schauberger, V. (1995). Energy of water. Yauza, Moscow.

3. Potapov, Yu.S., Fominskii, L.P., Potapov, S.Yu. (2001). Rotation energy. http://www.vixri.com/d/a fizika/Potapov\%20Ju.S.\%20_\%20\%20Energija\%20 vrashenija.pdf

4. Fominsky, L.P. (2004). Superheater heat generators - bluff or reality? Reference Book of Industrial Equipment, vol. 2, 81-93.

5. Fominskii, L.P. (2003). Rotary generators of free heat. Do it yourself. OKO-Plus, Cherkasy.

6. Osipenko, S.B. (1980). Hydrodynamic analysis of a pulsating body-propulsion system. Applied Mechanics, vol. 16 , no. $3,166-172$.

7. Lemysh, A. (2015). Physicists confirmed: The Rossi generator is working! https://www.chitalnya.ru/ work/1153533/

8. Alvarez, L.W. (1957). Catalysis of nuclear reactions by mesons. Physical Review, vol. 105, 1127-1128.

9. Akmatov, B.Zh., Tashpolotov, Y. (2015). Patent 1824, Fh, 24H 1/20. Kyrgyz Republic. "A device for efficient generation of thermal energy from a fluid based on electrophysical ionization" applicant and patent holder authors. Kyrgyzpatent. No 20150051.1; declare 04/27/2015; publ. 02.29.2016, Bull. No. 2 (Fch., F24H 1/20). patent.kg/doc/im/2016/2.pdf

10. Navigating the TehTab.ru directory. http://tehtab.ru/Guide/ GuideMedias/GuideWater/GuideWater1bar0to100deg/

11. Akmatov, B.Zh. (2015). The efficiency of electrophysical ionization (EFI) in generating thermal energy from a fluid. Vestnik, vol. 1, 152-157.

12. Osipenko, S.B. (2015). About the coefficient of efficiency. http://www.afuelsystems.com/arhdoc/400\%25.pdf

13. Gurov, K.P. (1966). Foundations of kinetic theory. Method of N.N. Bogolyubov. Nauka, Moscow.

14. Saveliev, V.I. (1970). Course of general physics. Vol. I. Science, Moscow.

15. Akmatov, B.Zh., Tashpolotov, U. (2013). "The ways of ionization of substances". Certificate number: 2148 (author's) Kyrgyz Republic. Kyrgyzpatent.

16. Potapov, Yu.S. (2004). New energy sources based on vortex heat generators (competitive material). Energy and Industry of Russia, vol. 7, no. 47. https:// www.eprussia.ru/epr/47/3155.htm

17. Kikoin, A.K. (1976). General course of physics. Nauka, Moscow.

18. Buinov, G.N. (1995). Thermal electrolysis inverser alternative to a nuclear reactor. Journal of Russian Physical Thought, vol. 1, 150-162.

19. Gofman, Yu.V. (1977). Laws, formulas, problems of physics. Naukova Dumka, Kyiv.

Paper submitted: 22.02.2021.

Paper accepted: 07.05.2021.

This is an open access article distributed under the CC BY 4.0 terms and conditions. 